\title{
Survey on the Use of Nuclear Renal Imaging in the United States
}

\author{
Kelly D. Archer, CNMT, and Norman E. Bolus, MSPH, MPH, CNMT, FSNMMI-TS \\ School of Health Professions, University of Alabama at Birmingham, Birmingham, Alabama
}

CE credit: For CE credit, you can access the test for this article, as well as additional JNMT CE tests, online at https://www.snmmilearningcenter.org. Complete the test online no later than December 2019. Your online test will be scored immediately. You may make 3 attempts to pass the test and must answer $80 \%$ of the questions correctly to receive $1.0 \mathrm{CEH}$ (Continuing Education Hour) credit. SNMMI members will have their CEH credit added to their VOICE transcript automatically; nonmembers will be able to print out a CE certificate upon successfully completing the test. The online test is free to SNMMI members; nonmembers must pay $\$ 15.00$ by credit card when logging onto the website to take the test.

Throughout the years, the role of nuclear medicine departments in the care of renal patients has changed as a result of technologic advancements and other factors. This study evaluated the current role of nuclear renal imaging. Methods: A survey was generated with questions about patient populations, the clinical indications most often seen, radiopharmaceutical use, measurement techniques, the average number of scans completed, and medical center/transplant team affiliations. The survey was sent to recipients on a mailing list acquired from the Nuclear Medicine Technology Certification Board. Results: Most of the responses came from departments in the southeastern United States. Most of the patient population is suburban. Nephrologists are the most common referring physicians for renal imaging. Most departments complete fewer than 10 renograms per month, and most departments use $99 \mathrm{mTc}$-mercaptoacetyltriglycine as the radiopharmaceutical of choice. A camera-based measurement technique is used most often. Most departments report being affiliated with a medical center, but only about half of those medical centers perform renal transplantation. The most commonly seen clinical indication for renal imaging is renal obstruction, whereas the least commonly seen is urine leakage. Conclusion: These results provide a better understanding of the current role of nuclear medicine in the care of renal patients and how this role has changed over the years.

Key Words: renal; utilization; survey

J Nucl Med Technol 2016; 44:223-226

DOI: 10.2967/jnmt.116.181339

\section{A} dvances in the field of medicine over the yearsparticularly improved radiologic techniques and their introduction into other modalities-have affected nuclear

\footnotetext{
Received Jul. 19, 2016; revision accepted Oct. 17, 2016.

For correspondence or reprints contact: Kelly Archer, UAB School of Health Professions, Room 446, 1705 University Blvd., Birmingham, AL 35294. E-mail: kellydee@uab.edu

Published online Oct. 27, 2016.

COPYRIGHT (c) 2016 by the Society of Nuclear Medicine and Molecular Imaging, Inc.
}

medicine imaging, increasing its role in some cases and decreasing its role in others. One of these roles is the care of renal patients. This study gathered data about renal imaging, radiopharmaceutical use, and patient populations via a survey of nuclear medicine departments across the United States. These data were used to determine the current role of nuclear medicine and how it has changed.

Some of the clinical indications for nuclear renograms include evaluation of renal obstruction, hydronephrosis, renovascular hypertension, urine leakage, split renal function, renal function in living related donors and transplant recipients, and renal function in patients with spinal cord injuries. The exact role of nuclear renograms in the care of this patient population has been unclear because of differences in use across different departments, some of which give it a much larger role than others. Our study was designed to clarify the current role and predict the future role.

One question was the type of radiopharmaceutical being used for renal imaging. In 1989 (1), the radiopharmaceuticals being used included ${ }^{131} \mathrm{I}$ - or ${ }^{123} \mathrm{I}$-labeled orthoiodohippurate or ${ }^{99 \mathrm{~m}} \mathrm{Tc}-$ mercaptoacetyltriglycine (MAG3), which at the time was an investigational drug but gaining a good reputation because its "clearance was closely correlated with [orthoiodohippurate] clearance."

By 1991 (2), the radiopharmaceuticals being used included ${ }^{99 \mathrm{~m}} \mathrm{Tc}$-glucoheptonate, ${ }^{99 \mathrm{~m}} \mathrm{Tc}$-dimercaptosuccinic acid, ${ }^{99 \mathrm{~m}} \mathrm{Tc}$-diethylenetriaminepentaacetate (DTPA), the newly Food and Drug Administration-approved ${ }^{99 \mathrm{~m} T c-}$ MAG3, and ${ }^{131}$ I-hippuran. With regard to effective renal plasma flow, ${ }^{131}$ I-hippuran was the radiopharmaceutical of choice whereas ${ }^{99 \mathrm{~m} T c-M A G 3}$ was growing in popularity because of its ability to be "taken up in very high quantities [and] give excellent renal images." $99 \mathrm{~m}$ Tcglucoheptonate and ${ }^{99 \mathrm{~m}} \mathrm{Tc}$-dimercaptosuccinic acid were the pharmaceuticals of choice for parenchymal imaging. Like today, ${ }^{99 \mathrm{~m}}$ Tc-DTPA and ${ }^{99 \mathrm{~m}} \mathrm{Tc}-\mathrm{MAG} 3$ were the top choice for evaluating blockage in the urinary tract. 
TABLE 1

Average Monthly Scans

\begin{tabular}{lc}
\hline No. of scans & Response \\
\hline$<10$ & $74 \%$ \\
$10-20$ & $17 \%$ \\
$>20$ & $9 \%$
\end{tabular}

Scanning for transplant patients was being done via perfusion studies using ${ }^{131} \mathrm{I}$-hippuran, ${ }^{99 \mathrm{~m}} \mathrm{Tc}$-DTPA, or 99mTc-MAG3 - similar to practice today with the exception of ${ }^{131} \mathrm{I}$. For patients with renovascular hypertension, ${ }^{131}$ I-hippuran or ${ }^{99 \mathrm{~m}} \mathrm{Tc}-\mathrm{DTPA}$ was being used, but compared with current practice, captopril was being given over a longer period before the scan.

By 2011 (3), very few changes had occurred. ${ }^{99 \mathrm{~m}} \mathrm{Tc}$ DTPA was still the radiopharmaceutical of choice among glomerular tracers, as was ${ }^{123} \mathrm{I}$ - or ${ }^{131} \mathrm{I}$-hippuran and ${ }^{99 \mathrm{~m}} \mathrm{Tc}-$ MAG3 among tubular tracers.

Between 2011 and today, some changes have occurred (4): "123I- and ${ }^{131}$ I-[orthoiodohippurate] are no longer commercially available in the United States because of the introduction of ${ }^{99} \mathrm{~m}$ Tc-MAG3, the poor imaging characteristics of ${ }^{131} \mathrm{I}$, potential of ${ }^{131} \mathrm{I}$-[orthoiodohippurate] for delivering a high radiation dose, and the unfavorable logistics resulting from the relatively short halflife of ${ }^{123}$ I."

Another question was the types of clinical indications being referred for renography. The overall role of nuclear medicine in the care of renal patients has decreased in recent years as other modalities have gained equal or better results for the same clinical indications. For example, cystography is often performed in nuclear medicine to evaluate vesicoureteral reflux, but a study has suggested that as technology advances, cystography will decrease in use and urosonography will increase (5). Another example is in the diagnosis of multicystic dysplastic kidney, which must be distinguished from hydronephrosis for treatment to be effective. A study found that for every patient in whom multicystic dysplastic kidney was diagnosed by renal ultrasound, the diagnosis was confirmed by nuclear medicine, suggesting that the nuclear renal scan is not necessary for this use (6). In contrast, the role of nuclear medicine may also increase because, as stated in one report, "these procedures are easy to perform and carry a low radiation burden, and sedation is not required" (7). Another report stated that "radionuclide imaging provides valuable information on renal function that cannot be obtained with other imaging modalities" and suggested that the role of nuclear medicine would grow because of its unique ability to relate perfusion to function (8).

\section{MATERIALS AND METHODS}

Using a mailing list acquired from the Nuclear Medicine Technology Certification Board, we emailed a link to a 9-question SurveyMonkey survey (SurveyMonkey, Inc.) to approximately 12,500 nuclear medicine departments across the United States. The questions were about the number of scans each month, the types of radiopharmaceutical used, the geographic location of the department, the patient population, and the type of referring physician. We received about 420 responses $(3.7 \%)$.

The first question asked how many renograms, on average, are completed each month: less than 10,10-20, or more than 20. The second question asked whether most of the patient population is inner city urban, non-inner city urban, suburban, rural, or military. The third question asked where the department is located geographically: southeast, southwest, midwest, northeast, or west. The fourth question asked which physician group most often refers renal patients to the department: primary care physicians, nephrologists, or surgeons. The fifth question asked which radiopharmaceutical is used most often: ${ }^{99 \mathrm{~m} T c-M A G 3,}{ }^{99 \mathrm{~m}} \mathrm{Tc}-\mathrm{DTPA}$, or another (free text). The sixth question asked whether the department uses a camera or a blood-based measurement technique. The next two questions asked whether the department is affiliated with a medical center and, if so, whether this medical center performs renal transplantation. The final question asked for a ranking of the indications seen most often to those seen least often: renal obstruction, renovascular hypertension, spinal cord injury, renal transplantation, split renal function, urine leakage, and others (free text).

\section{RESULTS}

Seventy-four percent of the departments perform less than 10 scans per month, $17 \%$ perform $10-20$, and $9 \%$ perform more than 20 (Table 1). For $40 \%$ of the departments, most patients are suburban; for $23 \%$, most are rural; for $18 \%$, most are inner city urban; for $13 \%$, most are noninner city urban; and for $3 \%$, most are military (Fig. 1).

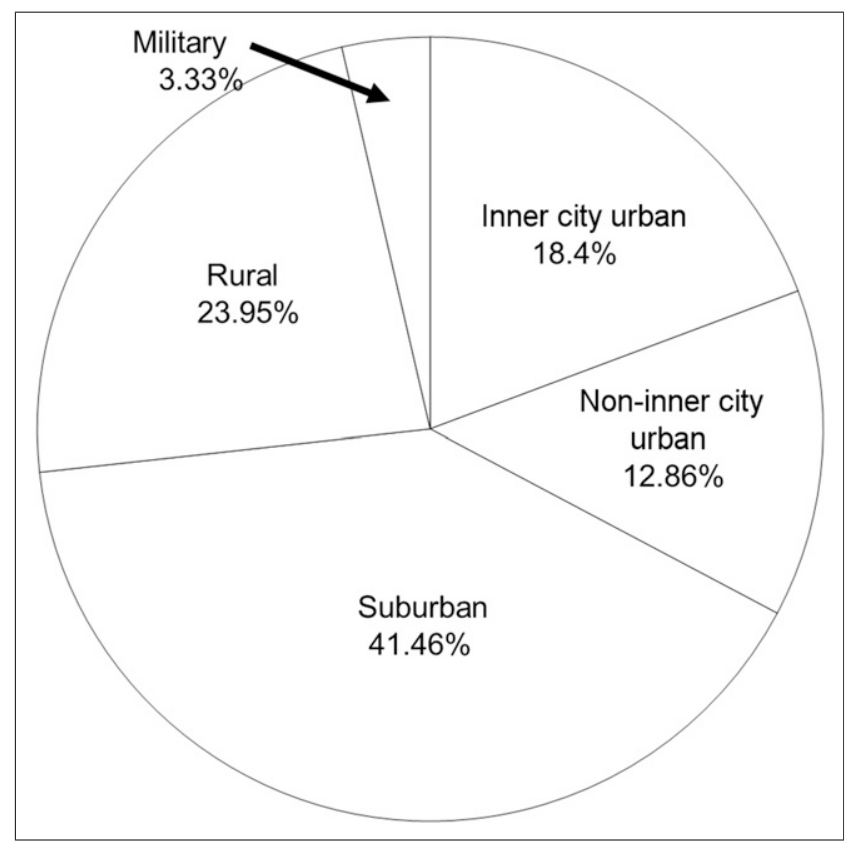

FIGURE 1. Patient population. 


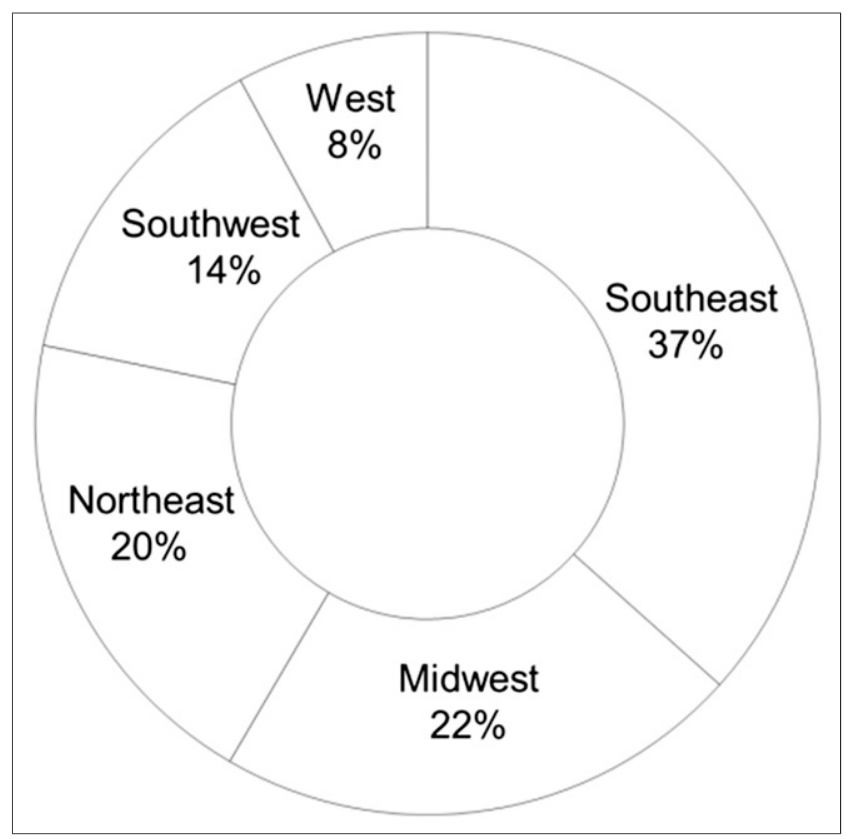

FIGURE 2. Geographic location.

Thirty-seven department are in the southeast, $22 \%$ in the midwest, $20 \%$ in the northeast, $14 \%$ in the southwest, and $8 \%$ in the west (Fig. 2). Sixty-four percent of the departments receive referrals most often from nephrologists, $17 \%$ from primary care physicians, and $4 \%$ from surgeons (Fig. 3). Ninety-one percent of the departments use ${ }^{99 \mathrm{~m}} \mathrm{Tc}-$ MAG3 most often, and the other 9\% use ${ }^{99 m}$ Tc-DTPA most often; some use a combination of the two. Ninetyone percent of the departments use a camera-based measurement technique, whereas only $9 \%$ use a blood-based technique. Seventy-six percent of the department are affiliated with a medical center, and $45 \%$ of those medical centers perform renal transplantation (Figs. 4 and 5). The clinical indications from most common to least common

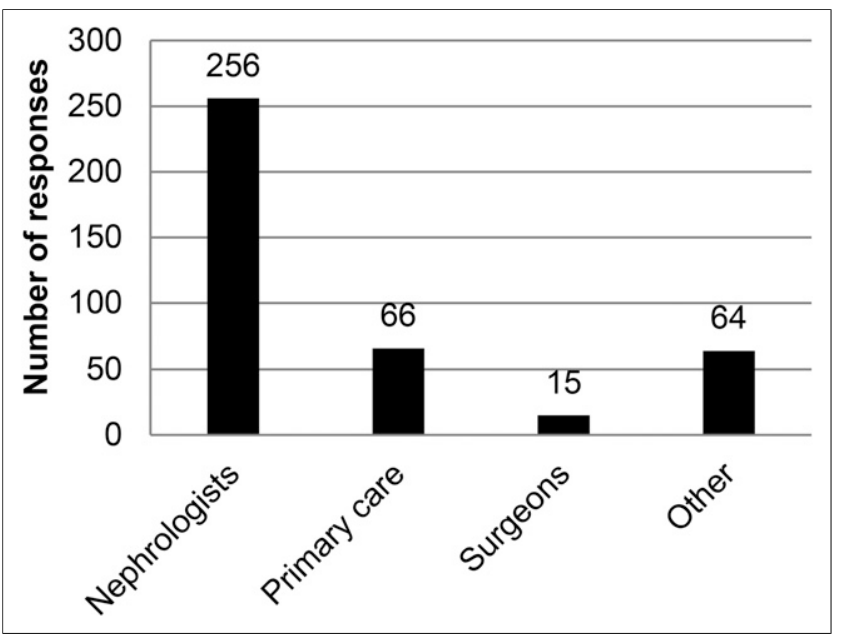

FIGURE 3. Referring physician data.

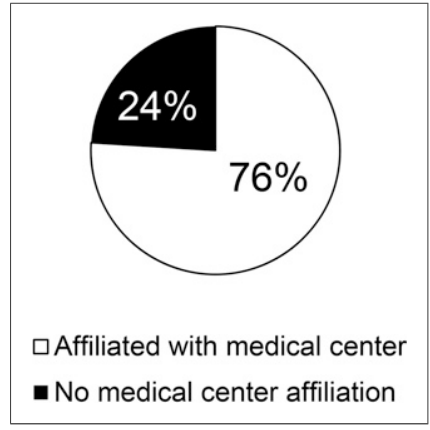

FIGURE 4. Medical center affiliation data.

are renal obstruction, split renal function, renovascular hypertension, renal transplantation, spinal cord injury, urine leakage, and, as free-text entries, chronic kidney disease and cancer.

\section{DISCUSSION}

One limitation of this study was a lower response rate than desired. In addition, because most data represent the southeast, the data may be skewed to represent this area more than the other areas. Finally, it was difficult to analyze the clinical indication data because the way the question was presented resulted in a wide variety of responses.

A few improvements should be considered for future such studies. Multiple mailing lists can be used to reach a greater variety of respondents and possibly achieve a better response rate. Also, to get a better variety of responses from each region, researchers can target them separately instead of sending a mass email to all. To achieve a better response rate, a follow-up email can be sent a week or two after the initial one-a step not possible in the current study for logistical reasons. To simplify analysis, the question about clinical indications could be reformatted to ask what percentage of patients with each clinical indication comes to the department. The survey elicited data strictly from a technologist's viewpoint, not from the viewpoint of a referring physician. Future studies could send a similar survey to both technologists and physicians to check for differences in perspective.

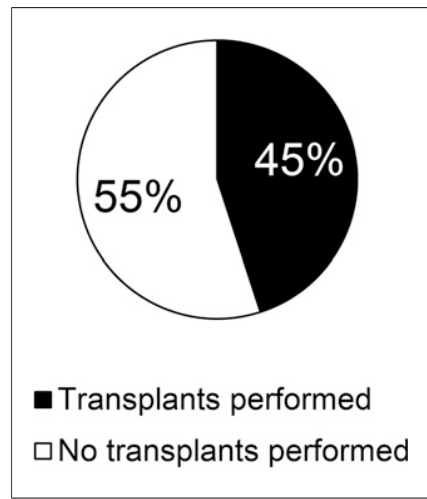

FIGURE 5. Are transplants performed at medical center? 


\section{CONCLUSION}

Our survey found that most respondents were from the southeastern United States; most patients are suburban and referred by nephrologists; fewer than 10 scans are completed each month; ${ }^{99}$ Tc-MAG3 is used most often as the radiopharmaceutical; a camera method is used most often for measurements; most department are affiliated with medical centers, only half of which perform renal transplantations; and renal obstruction is the most common indication whereas urine leakage is the least common. These results give the nuclear medicine community a better understanding of the current role of nuclear medicine in the care of renal patients.

\section{DISCLOSURE}

No potential conflict of interest relevant to this article was reported.

\section{REFERENCES}

1. Russell CD, Dubovsky EV. Measurement of renal function with radionuclides. J Nucl Med. 1989;30:2053-2057.

2. Blaufox MD. Procedures of choice in renal nuclear medicine. J Nucl Med. 1991;32:1301-1309.

3. Durand E, Chaumet-Riffaud P, Grenier N. Functional renal imaging: new trends in radiology and nuclear medicine. Semin Nucl Med. 2011;41:61-72.

4. Taylor AT. Radionuclides in nephrourology, part 1: radiopharmaceuticals, quality control, and quantitative indices. J Nucl Med. 2014;55:608-615.

5. Ascenti G, Zimbaro G, Mazziotti S, Chimenz R, Baldari S, Fede C. Vesicoureteral reflux: comparison between urosonography and radionuclide cystography. Pediatr Nephrol. 2003;18:768-771.

6. Whittam BM, Calaway A, Szymanski KM, et al. Ultrasound diagnosis of multicystic dysplastic kidney: is a confirmatory nuclear medicine scan necessary? J Pediatr Urol. 2014;10:1059-1062.

7. He W, Fischman AJ. Nuclear imaging in the genitourinary tract: recent advances and future directions. Radiol Clin North Am. 2008;46:25-43.

8. Aktaș A. Transplanted kidney function evaluation. Semin Nucl Med. 2014;44: 129-145. 